\title{
Aspectos da vigilância epidemiológica da raiva no município de Jacarezinho, Paraná, Brasil, 2003
}

\section{Aspects of the rabies epidemic surveillance in the municipal District of Jacarezinho, Paraná, Brazil, 2003}

\author{
Rita Luiza Piazentin Rolim¹; Fabiana Maria Ruiz Lopes ${ }^{2}$; Italmar Teodorico Navarro ${ }^{3 *}$
}

\section{Resumo}

A raiva é uma zoonose de etiologia viral que apresenta quatro ciclos de transmissão: urbano, rural, silvestre terrestre e silvestre aéreo. Independente do ciclo, não existe tratamento específico para a doença, e a profilaxia pré ou pós-exposição ao vírus rábico, deve ser rigorosamente executada. O objetivo deste trabalho foi descrever e analisar aspectos do atendimento prestado pelo serviço de saúde às pessoas agredidas por cães e gatos no município de Jacarezinho - Paraná, em 2003. O atendimento ao paciente é centralizado e prestado pela Vigilância Epidemiológica Municipal e a observação dos animais agressores é realizada pela Vigilância Sanitária Municipal. As variáveis estudadas foram obtidas dos registros da Ficha Clínica de Animais Agressores. Assim, indivíduos mais freqüentemente expostos foram crianças de até quatorze anos, do sexo masculino, por mordedura nos membros inferiores. No sexo feminino há grande incidência de agressões na faixa etária acima de cinqüenta anos, com a localização da mordedura nas mãos. As agressões ocorreram com maior freqüência fora do domicílio e os cães foram os principais responsáveis. As agressões cometidas por gatos ocorreram na maioria das vezes dentro do domicílio da vítima. Julho foi o mês de maior concentração de agressões e a maior incidência foi na faixa etária de dez a quatorze anos. Os resultados concluem quanto à importância da implantação permanente de programas educativos que promovam a posse responsável e conhecimento dos cuidados que o homem deve dedicar aos animais de companhia principalmente com relação à vacinação anti-rábica anual destes animais.

Palavras- Chave: Raiva, vigilância epidemiológica, prevenção, controle

\begin{abstract}
The rabies is a viral etiology disease in animals and presents four transmission cycles: urban, rural, terrestrial sylvan and aerial sylvan. No matter the cycle, there is no specific treatment for the disease. The fear to damage is high and the prophylaxis pre or pos-exposition to the rabic virus must be rigorously done. The main aim of this present study was to describe and analyze some aspects of attention paid by service from the city of Jacarezinho - Paraná, in the 2003. The attention to patients is centralized and paid by Municipal Epidemiological Surveillance and the observation to aggressive animals is done by Municipal Sanitarian Surveillance. The variables studied were got from files of Archives of Aggressive
\end{abstract}

\footnotetext{
1 Médica Veterinária - Pós graduanda do Curso de Saúde Pública e Ação Comunitária pelo INBRAPE - Londrina e FAFIJA Jacarezinho-PR.

2 Bióloga, Pós graduanda em Ciência Animal (Sanidade Animal) - Departamento de Medicina Veterinária Preventiva -CCA/ Universidade Estadual de Londrina.

3 Médico Veterinário, Professor Associado, Departamento de Medicina Veterinária Preventiva -CCA/Universidade Estadual de Londrina, Londrina-PR. E-mail: italmar@uel.br.

* Autor para correspondência.
} 
Animals Attendance. Thus, people more frequently exposed were made kid until 14 years old, male, by biting on inferior limbs of the body. On females aggressions often happen on women over 50 years, with bites on the hands. The aggressions happened more frequently out of homes and the dogs were held responsible for them. The aggressions done by cats happened mostly inside the victim's home. July was the month of greatest concentration of aggressions and most of them the age group from 10 to 14 years. The results conclude how important is a permanent implantation of teaching programs that cause the responsible ownership and knowledge of the cares that men must take with pets and awareness of community to need of a yearly vaccine against rabies on these animals.

Key words: Rabies, epidemiologic surveillance, prevention, control

\section{Introdução}

A raiva é uma zoonose de etiologia viral, cujo vírus pertence à família Rhabdoviridae e gênero Lyssavirus. É transmitida ao homem por mamíferos através da inoculação do vírus rábico existente na saliva do animal infectado, principalmente pela mordedura, podendo, também, ocorrer por arranhadura e lambedura (BRASIL, 2004a). A doença está presente em todos os continentes e tem um comportamento endêmico na maioria dos países da África e da Ásia. Apresenta quatro ciclos de transmissão: o ciclo urbano, o ciclo rural, o ciclo silvestre terrestre e o ciclo silvestre aéreo (BRASIL, 2004b).

Independente do ciclo, não existe tratamento específico para a doença, portanto, a profilaxia pré ou pós-exposição ao vírus rábico, deve ser rigorosamente executada (COSTA et al., 2000).

Segundo Costa et al. (2000) a raiva é uma doença passível de eliminação, quando no ciclo urbano, pois apresenta uma alta preventabilidade permitindo medidas eficientes de intervenção tanto junto ao ser humano quanto à fonte de infecção animal. Poucos países conseguiram livrar-se da doença e outros mantêm seu ciclo urbano sob controle, ocorrendo casos esporádicos de transmissão por animais selvagens.

O Programa Nacional de Profilaxia da Raiva (PNPR) foi criado no Brasil em 1973 com o objetivo de promover atividades sistemáticas de combate à raiva humana mediante seu controle nos animais domésticos. Além disso, o programa visa o tratamento específico das pessoas agredidas ou que, se supõe, tenham tido contato com animais raivosos, já que o tratamento ainda é a única conduta capaz de prevenir a manifestação da doença (SCHNEIDER et al., 1996).
No PNPR, Schneider et al. (1996) destacaram, ainda, o conhecimento da população exposta ao risco, levando-se em conta algumas variáveis como: faixa etária, sexo, local de ocorrência, residência do agredido e do animal agressor, espécie agressora e sua situação vacinal. Estes itens são fundamentais para que se realize um trabalho dirigido, especialmente de educação sanitária, relacionada com os cuidado aos animais e os riscos da exposição às agressões.

O último caso de raiva canina ocorrida em Jacarezinho aconteceu em 1991 e, até o ano de 2002 foram realizadas campanhas de vacinação anti-rábica canina e felina. Pelo fato do município ter a raiva canina controlada e estar localizado em região de fronteira de Estado, são fatores determinantes para o aperfeiçoamento do programa de vigilância da pessoa agredida e do animal agressor, dentro da realidade do município.

O presente estudo teve por objetivo analisar os registros das observações realizadas em animais agressores, no município de Jacarezinho, PR, e oferecer subsídios para o aprimoramento das atividades de profilaxia da raiva, bem como seu controle e erradicação.

\section{Material e Métodos}

\section{Localização do Município}

Segundo dados do IBGE (2000), o município possui cerca de 39.580 habitantes e está localizado na região Norte do Paraná, a $153 \mathrm{~km}$ de Londrina e 392 km de Curitiba, latitude 230 09' 24" sul, longitude $49^{\circ} 58^{\prime} 16^{\prime \prime}$ oeste - GR e altitude de $435 \mathrm{~m}$. 


\section{População estudada}

A Secretaria de Estado da Saúde do Paraná, Divisão de Zoonoses e Intoxicações, define para o cálculo das populações, as seguintes proporções: população canina, $15 \%$ do número de habitantes do município; população felina, $20 \%$ da população canina. No ano de 2002, as populações estimadas de cães e gatos eram de 5.937 e 1.187, respectivamente, em Jacarezinho, de acordo com os dados apresentados pela Secretaria de Administração do Município (SAM) $/ 19^{a}$ Regional de Saúde (comunicação pessoal).

\section{Atendimento das pessoas agredidas}

$\mathrm{O}$ atendimento das pessoas agredidas por animais foi realizado de maneira centralizada, pelo Serviço de Vigilância Epidemiológica localizado no Centro de Saúde de Jacarezinho, no Posto de Saúde Central.

\section{Observação dos animais agressores}

Os animais agressores foram submetidos à observação clínica por um técnico da Vigilância Sanitária Municipal, por dez dias, a contar do dia da agressão.

A observação clínica do animal agressor norteia a conduta frente ao tratamento profilático da raiva humana: necessidade ou não da vacina, número de doses e interrupção ou não do tratamento.

\section{Avaliação das fichas epidemiológicas}

Foram levantadas 249 fichas de pacientes que procuraram atendimento, pós-agressão, que receberam ou não tratamento anti-rábico pósexposição, durante o ano de 2003. A ficha utilizada pela Vigilância Epidemiológica é composta de três partes (picotadas e destacáveis), sendo elas: a) Ficha
Individual de Atendimento Anti-Rábico Humano, que contém dados sobre o paciente e sobre a exposição; b) Ficha de Identificação do Paciente (FIP), que é destacada e entregue ao usuário para a seqüência do esquema vacinal; c) Ficha Clínica de Animais Agressores (FCAA) que é encaminhada à Vigilância Sanitária para a observação do animal.

O preenchimento das fichas foi efetuado por técnicos da Vigilância Epidemiológica Municipal. As informações referentes às pessoas agredidas foram: faixa etária e sexo do agredido, local de residência do ferido, data da ocorrência da agressão e localização do ferimento. E quanto ao animal agressor os itens analisados foram: espécie do animal, residência ou local, situação clínica e vacinal e se a agressão ocorreu no domicílio, obtidas da Ficha de Observação de Animais Agressores. Os resultados foram analisados por meio do Programa Epi Info 6,04 (CDC-Atlanta-USA).

\section{Resultados}

Da análise das 249 fichas epidemiológicas, obtiveram-se os resultados descritos a seguir: os indivíduos mais freqüentemente expostos às agressões de estão na faixa etária entre um a quatorze anos (48\%), com elevado índice entre cinco e nove anos (Figura 1).

Quanto ao sexo dos atendidos, 54\%, são do sexo masculino e $46 \%$ do sexo feminino (Figura 2).

Considerando a idade e o sexo, a população de faixa etária entre um e quatorze anos observou-se que os meninos prevaleceram como os mais expostos às agressões, especialmente na faixa etária de cinco a nove anos. Analisando os resultados da população com idade maior ou igual a cinqüenta anos, observamos que as mulheres são mais suscetíveis à agressão do que os homens (Figura 3). 


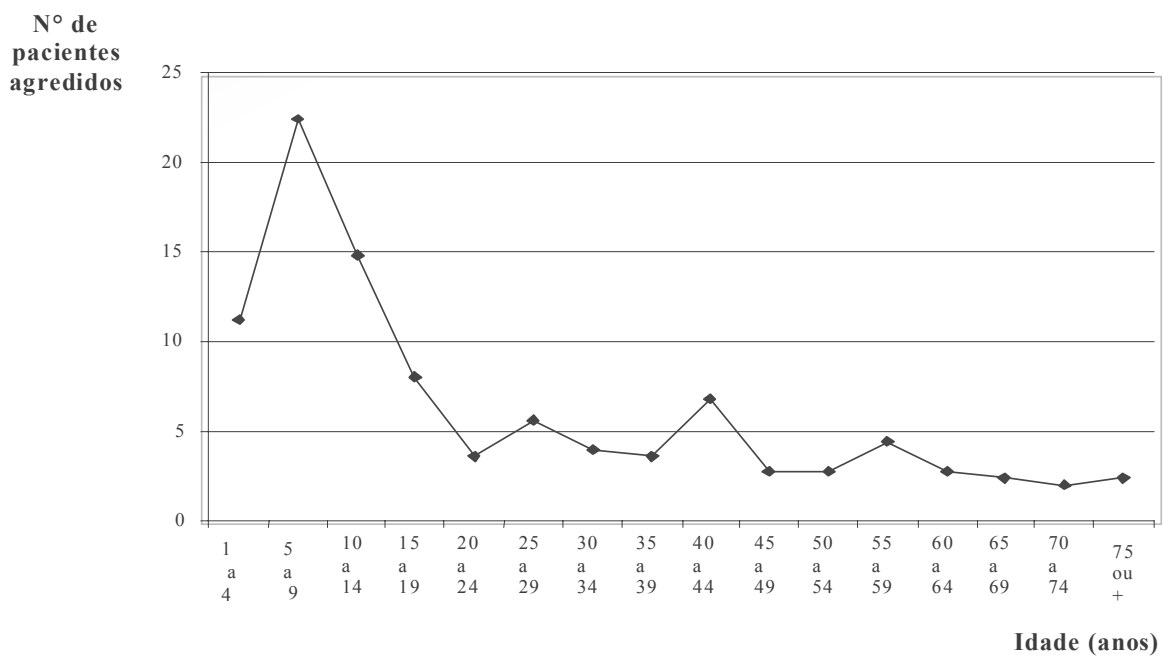

Figura 1. Incidência das agressões em pacientes atendidos pela Vigilância Epidemiológica Municipal, segundo a faixa etária, Jacarezinho-PR, 2003.

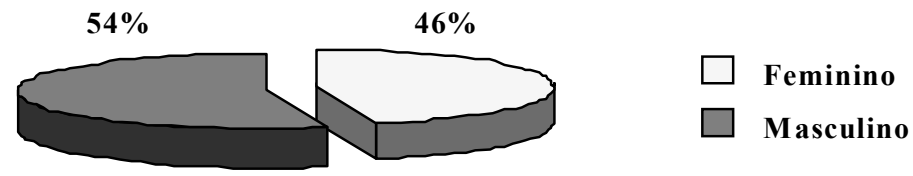

Figura 2. Pacientes agredidos por animais atendidos pela Vigilância Epidemiológica Municipal, segundo o sexo, Jacarezinho-PR, 2003.

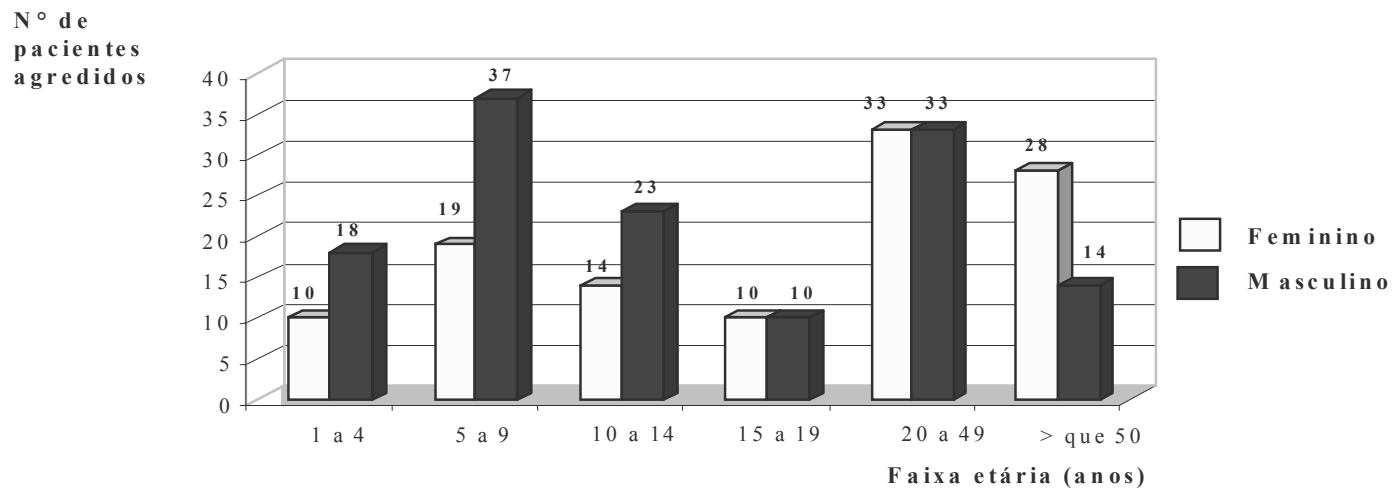

Figura 3. Pacientes agredidos por animais atendidos pela Vigilância Epidemiológica Municipal, associando o sexo e a faixa etária, Jacarezinho-PR, 2003. 
A maior freqüência das agressões animais ocorreu fora do domicílio do paciente, acontecendo em $71 \%$ dos casos (Figura 4). As faixas etárias mais expostas às agressões fora do domicílio são os adultos (de vinte a quarenta e nove anos) e das crianças (de cinco a nove anos). Considerando as agressões dentro do domicílio os adultos foram os mais acometidos (Figura 5).

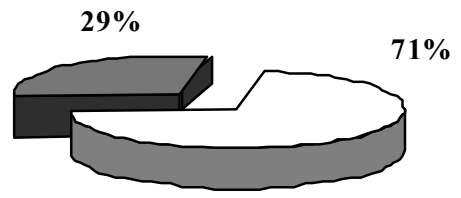

Fora do domicílio

Dentro do domicílio

Figura 4. Freqüência das agressões em relação ao domicílio dos pacientes atendidos pela Vigilância Epidemiológica Municipal, Jacarezinho-PR, 2003.

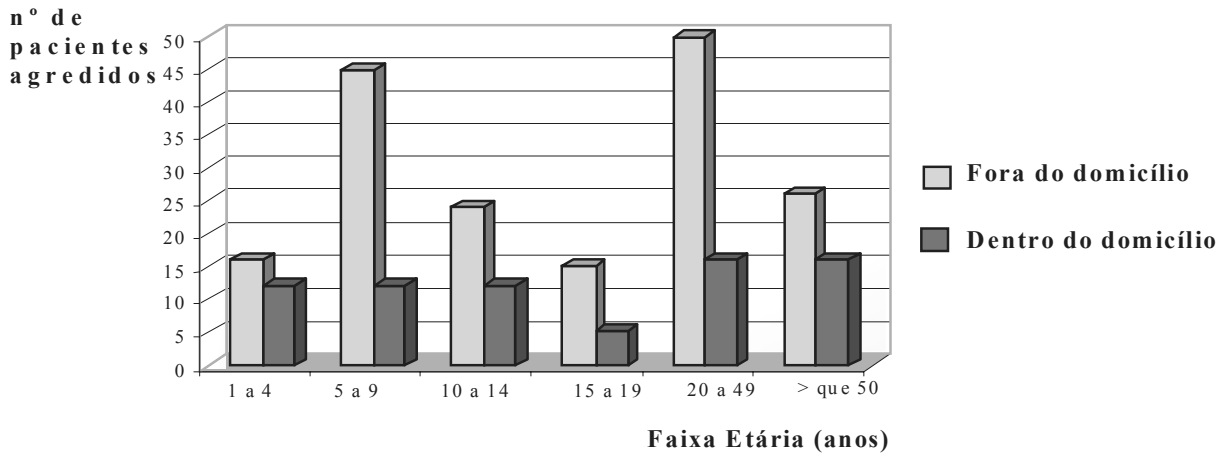

Figura 5. Número de agressões em relação ao domicílio do paciente e faixa etária, Jacarezinho-PR, 2003.

Os animais responsáveis pelas agressões, em ordem decrescente de incidência, foram: cães $(91,2 \%)$, gatos $(8,4 \%)$ e outros $(0,4 \%)$, sendo que neste último houve um relato de um cavalo que agrediu o proprietário. Os cães foram responsáveis pela maioria das agressões fora do domicílio (69\%), enquanto o maior número das agressões causadas por gatos ocorreu dentro do domicílio.

Em todas as faixas etárias dos pacientes que sofreram algum tipo de agressão, prevaleceu o cão como o animal responsável pelo maior número das agressões (Figura 6).

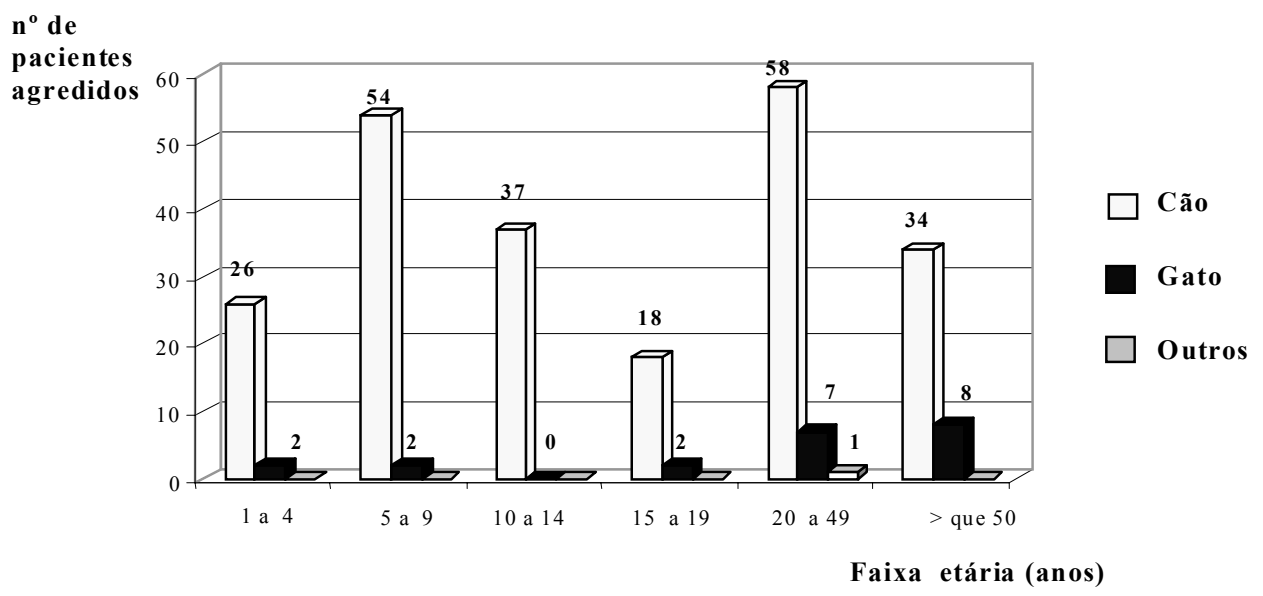

Figura 6. Número de agressões por espécie de animal e faixa etária dos pacientes atendidos pela Vigilância Epidemiológica Municipal, Jacarezinho-PR, 2003. 
Em relação à condição de imunização anti-rábica, constatou-se que de um total de 227 cães agressores $60,4 \%$ estavam vacinados e, de um total de 21 gatos $14,3 \%$ eram vacinados. Além disso, $31,2 \%$ das pessoas agredidas por cães e $57,1 \%$ das pessoas agredidas por gatos não informaram se os animais foram vacinados ou não.

Quanto ao estado clínico dos animais agressores $96,8 \%$ encontravam-se sadios no momento da agressão, mantendo-se assim até o final da observação clínica. A proporção de animais que morreram e/ou desapareceram durante a observação

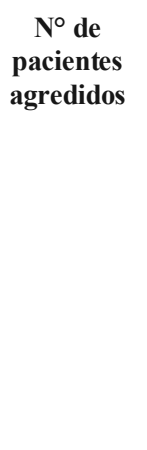

foi de $2 \%$, no entanto, não foram observados $1,2 \%$ dos animais agressores.

Dos 249 pacientes que procuraram a Vigilância Epidemiológica do Município de Jacarezinho, 105 $(42,2 \%)$ sofreram mordedura nos membros inferiores, $71(28,5 \%)$ nas mãos e pés, $38(15,3 \%)$ nos membros superiores, $16(6,4 \%)$ no tronco, $15(6 \%)$ na cabeça/ pescoço e quatro $(1,6 \%)$ na mucosa. Quando relacionou-se a localização do ferimento com a espécie animal causadora da agressão, a incidência é maior nas mãos e pés quando o gato é o animal agressor $(47,6 \%)$ e nos membros inferiores quando o causador é o cão $(44,1 \%)$ (Figura 7$)$.

Figura 7. Incidência de mordeduras em pacientes atendidos pela Vigilância Epidemiológica Municipal, de acordo com a localização do ferimento e o animal agressor, Jacarezinho-PR, 2003.

Em relação à faixa etária observou-se que $26,8 \%$ das mordeduras localizadas na cabeça/pescoço aconteceram em crianças até nove anos, com grande incidência na faixa de um a quatro anos, como ocorre também na mordedura de mucosa. A faixa etária que mais sofreu agressões aos membros inferiores foi de quinze a dezenove anos (55\%). As agressões localizadas nas mãos e pés aparecem em percentagens maiores na faixa etária que compreende as idades superiores a cinqüenta anos.

A distribuição mensal dos casos de agressão apresentou maior concentração no mês de julho $(14,5 \%)$, seguido dos meses de junho $(11,6 \%)$, janeiro $(10,4 \%)$, maio $(9,6 \%)$, Nos outros meses a proporção de procura à Vigilância Epidemiológica por agressão situou-se entre 4,4\% e 7,6\% (Figura 8).

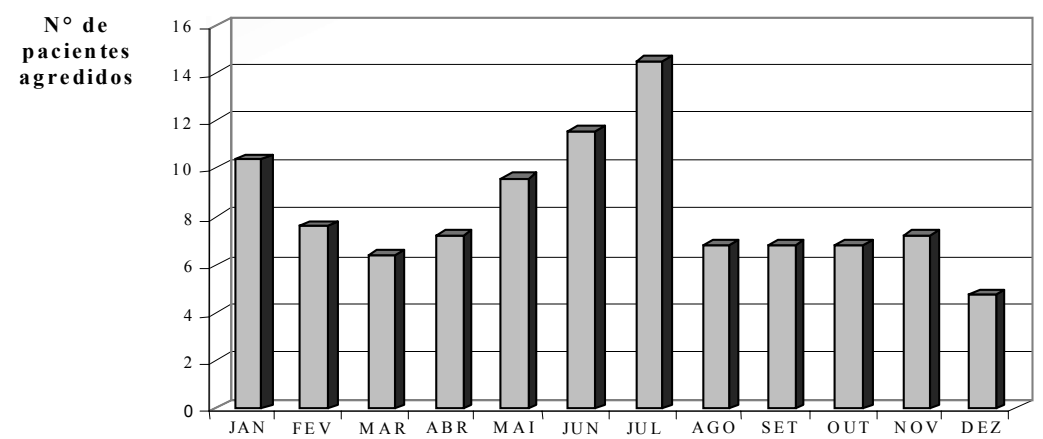

Figura 8. Distribuição mensal das agressões atendidas pela Vigilância Epidemiológica Municipal, Jacarezinho-PR, 2003. 
A maior incidência de agressões, segundo a faixa etária, ocorreu no mês de julho, em crianças de dez a quatorze anos $(35,1 \%)$. Nos outros meses houve um equilíbrio dentro de todas as faixas etárias, com destaque nos meses de abril e outubro com aumento de pacientes de quinze a dezenove anos, com $20 \%$ das agressões ocorridas.

Para a comparação de localizações do domicílio de pacientes que procuram o serviço em relação ao animal agressor, estabeleceu-se o critério de dividir a cidade em oito regiões, além da zona rural. Como a cidade de Jacarezinho possui 59 bairros sendo poucos conhecidos, foi considerado como referência o nome do maior bairro. Portanto a cidade ficou dividida nas seguintes regiões: Aeroporto, Centro, Jardim Alves, Jardim São Luiz, Nova Jacarezinho, Parque Bela Vista, Vila São Pedro e Vila Setti.

O maior número de pessoas que procuraram o serviço foi proveniente das regiões da Vila São Pedro (24,1\%), Centro (18,9\%), Aeroporto (14,5\%) e Vila Setti (14,5\%). Quanto ao domicílio dos animais agressores, $25,3 \%$ são da região da Vila São Pedro, $18,1 \%$ do Centro, $14,9 \%$ da Vila Setti e 14,5\% do Aeroporto.

Observou-se ainda que a maioria das pessoas são agredidas em sua própria região, sendo que os moradores do centro de Jacarezinho foram os que mais sofreram agressões em outras regiões da cidade.

\section{Discussão}

As variáveis trabalhadas neste estudo foram retiradas da Ficha Clínica de Animais Agressores. O item situação vacinal do animal em $31,2 \%$ dos cães e $57,1 \%$ dos gatos não foi preenchido. Os demais itens foram preenchidos a contento.

As faixas etárias mais expostas foram as inferiores a quinze anos e em indivíduos do sexo masculino, principalmente na faixa etária de cinco a nove anos. Explica-se este fato pela maior possibilidade de contato com animais, visto que os meninos permanecem a maior parte do tempo na rua, principalmente nos períodos de férias, sendo ainda comum as brincadeiras e atitudes que podem despertar a reação de agressividade nos animais. Outros autores encontram resultados semelhantes ao sexo e idade, como Carvalho, Soares e Franceschi (2002), Del Ciampo et al. (2000) e Garcia et al. (1999). Quanto ao sexo feminino, a maior incidência de agressões ocorreu em pessoas com idade superior a 20 anos. Situação semelhante foi observada por Carvalho, Soares e Franceschi (2002). Esta incidência é maior que no sexo masculino na mesma faixa etária, demonstrando que a mulher se expõe mais a acidentes, devido às atividades desenvolvidas pelas mesmas dentro de seus lares.

Quanto ao domicílio, o maior número de agressões ocorreu fora do domicilio do paciente, e a incidência foi maior nas faixas etárias de cinco a nove anos e vinte a quarenta e nove anos. Nos acidentes que aconteceram dentro do domicilio do paciente, observou-se que indivíduos acima de quinze anos são os mais expostos e que as mulheres acima de cinqüenta anos sofreram mais este tipo de acidente.

A participação do cão como animal agressor foi predominante $(91,2 \%)$, corroborando com os resultados de Carvalho, Soares e Franceschi (2002) (86,8\%), Del Ciampo et al. (2000) (87,4\%), Garcia et al. (1999) (52,3\%) e Schneider et al. (1996) $(83,2 \%)$.

Os cães foram os responsáveis pelos maiores números de agressões, tanto fora como dentro do domicílio do paciente. Analisando as agressões cometidas por gatos observamos que a maioria delas $(80,9 \%)$ ocorreu dentro do domicílio e principalmente em mulheres, e na faixa etária que corresponde à idade superior a cinqüenta anos. Isto pode ser a indicação de uma baixa procura ao serviço de pessoas agredidas por gatos. Neste caso, o acidente ocorreu em casa com o animal de estimação, e as pessoas não vêem neles algum tipo de risco ou possibilidade de infecção pelo vírus rábico.

O índice de cães e gatos vacinados $(60,4 \%$ e $14,3 \%$, respectivamente), é considerado baixo para uma cidade onde a campanha de vacinação anti- 
rábica foi realizada até o ano de 2002, cuja cobertura vacinal neste ano (2003) ficou acima da meta, alcançando o índice de 105,4\% (sendo 104,7\% cães e $108,76 \%$ gatos) (SAM $\left./ 19^{\mathrm{a}} \mathrm{RS}\right)$, e que muitos animais agressores podem ter sido vacinados e deveriam estar dentro da validade da vacina. Situação semelhante ao baixo índice de animais agressores vacinados foi encontrado nos estudos de Garcia et al. (1999) com 42,1\% de cães e 13,4\% de gatos com imunização anti-rábica prévia e de Carvalho, Soares e Franceschi (2002) com 34,2\% de animais vacinados. Dos pacientes que procuraram o serviço, $31,2 \%$ agredidos por cão e $57,1 \%$ por gatos, não informaram se os animais estavam vacinados ou não. A informação sobre o estado vacinal do animal é fornecida no momento do preenchimento da ficha e muitas vezes as pessoas desconhecem este dado, situação também encontrada no estudo de Carvalho, Soares e Franceschi (2002), com índice de 24,2\% do total dos animais agressores com a situação vacinal ignorada.

O estado clínico dos animais agressores durante e até o final da observação manteve-se normal (sadio) em $96,8 \%$ dos casos, sendo que foram observados no $1^{\circ}, 5^{\circ}$ e $10^{\circ}$ dia da agressão. Deixaram de ser observados 1,2\% dos animais por falta de informação do endereço do agressor e $2 \%$ referem-se aos animais que morreram ou desapareceram durante a observação.

Os locais do corpo mais atingidos foram os membros inferiores $(42,2 \%)$ e mãos/pés $(28,5 \%)$, sendo resultado semelhante aos observados por Carvalho, Soares e Franceschi (2002) e Del Ciampo et al. (2000), divergindo do estudo de Garcia et al. (1999), que teve em seus estudos os membros superiores e cabeça como os locais de maior índice de mordeduras. Observou-se que o cão foi responsável por $44,1 \%$ das agressões nos membros inferiores, que teve a maior incidência na faixa etária de quinze a dezenove anos, atribuindo-se esse resultado em função das áreas de lazer: ruas, praças e outros lugares públicos. Os gatos, por outro lado, responderam por $47,6 \%$ das agressões nas mãos/ pés, ocorridas principalmente na faixa etária que inclui as idades acima de cinqüenta anos, uma vez que a maioria dos casos ocorreu dentro do domicílio e pode ser explicado pela facilidade de manipulação destes animais, muitas vezes de estimação, por pessoas mais idosas.

Na distribuição mensal das agressões ocorridas em Jacarezinho no ano de 2003, observou-se um aumento de procura ao serviço a partir do mês de maio, havendo uma concentração maior no mês de julho com $14,5 \%$ do total de pacientes. Carvalho, Soares e Franceschi (2002) obtiveram resultados semelhantes, sendo que as crianças da faixa etária de dez a quatorze anos foram as mais agredidas. Justifica-se pelo fato do mês de julho ser de férias escolares e as crianças ficarem expostas a acidentes com animais nas ruas e até mesmo dentro de casa.

A maior freqüência das agressões ocorreu na região da Vila São Pedro, local que apresenta maior densidade demográfica humana, por ter vários núcleos populacionais. Isso era esperado, pois, o aumento da população humana é determinante para o aumento da população animal (canina e felina). Estes resultados foram semelhantes aos obtidos por Garcia et al. (1999), que também observaram maior ocorrência das agressões em regiões mais populosas.

As pessoas, na maioria das vezes, são agredidas dentro da sua região de domicílio indicando que o animal agressor é conhecido da vítima, devendo-se a isso uma elevada incidência de animais observados.

\section{Conclusão}

Os resultados observados permitem as seguintes conclusões:

As crianças e idosos estão mais expostos às agressões;

O cão é o grande responsável pelas agressões, no entanto o gato foi responsável pela maioria das agressões em idosos, sendo a mão o local do corpo mais agredido nesta faixa etária; 
As agressões causadas por cães ocorreram em sua grande maioria fora do domicílio do pacientes, sugerindo que são semi-domiciliados;

A maioria das agressões atribuídas aos gatos ocorreram no domicílio e o próprio dono foi a vítima;

A Ficha de Observação de Animais Agressores necessita de revisão, visando o preenchimento da mesma com mais riqueza de informações.

\section{Recomendações}

É importante que dentro do Programa de Profilaxia da Raiva mantenha-se constante a vigilância que inclui a vacinação anti-rábica animal, coletas de tecido nervoso dos animais suspeitos para a análise laboratorial, observação clínica de todos os animais agressores e principalmente, a implantação permanente de programas educativos que promovam a posse responsável e conhecimento dos cuidados que o homem deve dedicar aos seus animais de companhia. Também é importante a conscientização da comunidade para a necessidade de vacinação antirábica anual destes animais e procura do serviço de saúde no momento da agressão, mesmo que o animal seja conhecido e vacinado.

\section{Referências}

BRASIL. Ministério da Saúde. Secretaria de Vigilância em Saúde. Boletim eletrônico Epidemiológico: SVS - Surto de raiva humana transmitida por morcegos no município de Portel - Pará, março/abril de 2004, v.4, n.6, 2004a. Disponível em: < http://portal.saude.gov.br/portal/ arquivos/pdf/boletim_eletronico_06_ano04.pdf $>$. Acesso em: 15 set. 2004.

BRASIL. Ministério da Saúde. Secretaria de Vigilância em Saúde. Departamento de Vigilância Epidemiológica. Doenças infecciosas e parasitárias: guia de bolso. Brasília, 2004b.

CARVALHO, W. O.; SOARES, D. F. P. P.; FRANCESCHI, V. C. S. Características do atendimento prestado pelo Serviço de Profilaxia da Raiva Humana na Rede Municipal de Saúde de Maringá - Paraná, no ano de 1997. Informe Epidemiológico do SUS, Brasília, v.11, n.1, jan. - mar, 2002. Disponível em: <http://dtr2001.saude.gov.br/ svs/pub/ Iesus/ies0111.htm\#03>. Acesso em: 15 set. 2004.

COSTA, W. A.; ÁVILA, C. A.; VALENTINE, E. J. G.; REICHMANN, M. L. A. B.; CUNHA, R. S.; GUIDOLIN, R.; PANACHÃO, M. R. I.; OMOTO, T. M.; BOLZAN, V. L. Manual técnico do Instituto Pasteur - Profilaxia da raiva humana. 2 ed. São Paulo: Instituto Pasteur, 2000.

DEL CIAMPO, L. A.; RICCO, R. G.; ALMEIDA, C. A. N.; BONILHA, L. R. C. M.; SANTOS, T. C. C. Acidentes de mordeduras de cães na infầncia. Revista de Saúde Pública, São Paulo, v.34, n.4, p.411 -412, 2000.

GARCIA, R. C. M.; VASCONCELLOS, S.; SAKAMOTO, S. M.; LOPEZ, A. C. Análise de tratamento anti-rábico humano pós-exposição na região da Grande São Paulo, Brasil. Revista de Saúde Pública, São Paulo, v.33, n.3, p.295-30, 1999.

IBGE: Instituto Brasileiro de Geografia e Estatística. Município de Jacarezinho. Disponível em: <http:// www.ibge.gov.br/cidadesat/default.php >. Acesso em: 15 set. 2004 .

SCHNEIDER, M. C.; ALMEIDA, G. A.; SOUZA, L. M.; MORARES, N. B.; DIAZ, R. C. Controle da raiva no Brasil de 1980 a 1990. Revista de Saúde Pública, São Paulo, v.30, n.2, p.196-203. 1996. 